\title{
Notas sobre a política de produtividade em pesquisa no Brasil: Consequências para a vida acadêmica, a ética no trabalho e a saúde dos trabalhadores
}

Madel T. Luz*

\section{Trajetória de uma reflexão}

C ste artigo situa-se na sequiência de alguns trabalhos, frutos de Eatividades de pesquisa sociológica desenvolvidas há uma década, sobre a busca de cuidados e práticas de saúde, suas possíveis relações com o regime de trabalho no capitalismo atual, e de reflexões sobre consequiências sociais da política educacional e de ciência e tecnologia brasileira relativas ao ensino superior, especificamente de pós-graduação (LUZ, 2003, 2004a 2004b, 2005b, 2007).

Nos três últimos (LUZ, 2005a, 2005b, 2007) discutimos a subordinação progressiva do ensino superior, ao longo dos últimos vinte anos, sobretudo no que tange o setor da formação em pósgraduação, à política do desenvolvimento tecnológico e científico do país, o regime social e ético de trabalho implicado nesta subordinação e as possíveis consequiências para a saúde dos trabalhadores: docentes $e$ pesquisadores. ${ }^{1}$

O ponto de partida dessas reflexões, situadas antes do início desta década, foi nossa perplexidade com a constatação empírica dos seguintes fenômenos: a) a busca crescente de cuidados e práticas de saúde ditos "alternativos" na população como um todo

Socióloga, doutora em Ciência Política pela USP, professora titular do Instituto de Medicina Social da UERJ, professora titular aposentada de Sociologia do Instituto de Filosofia e Ciências Sociais da UFRJ. Endereço eletrônico: madelluz@superig.com.br.

1 Reconhecemos que o travessão ou o hífen seriam grafias mais adequadas à situação atual dos professores de universidade. O uso da conjunção "e" (docentes e pesquisadores) é intencional. Visa a ressaltar a função fim principal da universidade, isto é, o ensino, mesmo o ensino canônico. A pesquisa deve ser a fonte do ensino. 
(LUZ, 1997, 2003), mas predominantemente no segmento social com educação superior, inclusive entre trabalhadores acadêmicos, especialmente os da área da saúde; ${ }^{2}$ b) o também crescente adoecimento dos profissionais da atenção médica: médicos, enfermeiros, e técnicos ligados à atenção, compatível com a demanda explosiva de cuidados médicos (LUZ, 2004a, 2005a); c) o processo social que denominamos, em homenagem à obra clássica dos anos 70 do filósofo e teólogo Ivan Ilich (ILLICH, 1975), de "nova onda de medicalização da vida" (LUZ, 2003), em desenvolvimento desde os anos 90, a partir da qual as biociências e as neurociências tendem a normatizar as transformações biopsíquicas no curso da vida das pessoas $^{3}$, vistas no período moderno como fazendo parte da natureza humana (LUZ, 2004b). O desconforto com mudanças nas fases da vida, os adoecimentos no decurso da existência, ou mesmo as manifestações ocasionais de insatisfação com o viver individual ou grupal, expressas em mudanças de humor, como tristeza e depressão, ou mesmo seus contrários, são vistos como desvios de parâmetros cada vez mais estritos de normalidade, cada vez mais precocemente aplicados aos indivíduos; e esses desvios, reduzidos a sintomas localizáveis em zonas do cérebro, "tratáveis" de forma preventiva ou curativa. As biociências adotam, assim, a perspectiva de uma utopia, a utopia da saúde (SFEZ, 1996).

Sociologicamente, interpretamos a marcha deste avanço científico, que denominamos nova onda de medicalização, como um

2 Provavelmente a presença marcante deste segmento social é devida à acessibilidade das práticas de cuidado em saúde ditas alternativas, ou complementares, às camadas médias educadas da população, em função do capital simbólico e material de que dispõem, possibilitando escolha terapêutica ou preventiva. Uma indicação neste sentido é o sucesso dessas práticas quando implantadas em programas do Sistema Único de Saúde ou em universidades, para onde convergem as camadas mais desprovidas de recursos (materiais, simbólicos). Existem até mesmo associações de pacientes em defesa da preservação de medicinas e práticas alternativas.

3 Em seu livro Nêmesis Médica - A expropriação da saúde, Illich denunciou a institucionalização médica da saúde dos cidadãos, por meio do conjunto de instituições que se ocupam do processo saúde e doença na sociedade contemporânea. Denominou este processo "medicalização social". No momento atual nos referimos não às instituições médicas, mas às biociências, e ao processo em curso de biomedicalização da vida humana. 
processo político que, embora resulte inegavelmente da revolução no conhecimento biológico, tende a tornar-se uma estratégia normativa da vida humana com consequiências sócio-políticas sérias, gerando conformismo coletivo, no nível da conduta e das representações sociais, pela redução dos crescentes sintomas de mal estar difuso nas pessoas e de formas coletivas de adoecimentos pouco detectáveis na lógica diagnóstica da racionalidade biomédica. As questões de saúde e doença (LUZ, 2004a, 2005a).

Adoecimentos que podemos classificar, por sua similaridade, constância, frequiência e quantidade de pessoas atingidas, como coletivos, motivadores de grande parte de absenteísmo e de dispensa no trabalho ${ }^{4}$, atingindo números recordes de milhões de horas no mundo da produção capitalista mundial, apesar da escassez e da precariedade atuais do emprego que a caracteriza e da retração da seguridade social e da atenção médica (JOUBERT, BERTOLOTTO \& BOUCHNIK, 1995; CASTEL, 1998; LUZ, 2004a) ${ }^{5}$.

4 Precisamos assinalar que há uma distinção a ser feita entre absenteísmo e dispensa do trabalho, pois a dispensa autoriza medicamente (isto é, legalmente) a ausência do trabalho, nem sempre sendo computada como absenteísmo. Somados o absenteísmo e a dispensa do trabalho, a massa de milhões de horas laborais perdidas em um ano torna-se impressionante, sendo tema de contínuas discussões no mundo empresarial, e em disciplinas como a saúde coletiva, a medicina e a sociologia do trabalho. Também a mídia impressa ocupa-se constantemente deste tema. Ainda hoje, no momento em que escrevemos estas notas, o diário popular carioca "O Dia" noticia que a principal dispensa no trabalho é motivada por "distúrbios psíquicos". Conforme reconhece o superintendente da perícia médica estadual do trabalho "mais da metade de 55 mil licenças concedidas em 2007 foram causadas por doenças psíquicas como depressão, síndrome do pânico e ansiedade" Quando trata-se de funcionários, as categorias mais atingidas por esses sintomas e síndromes são professores e agentes penitenciários. $\mathrm{O}$ superintendente recomenda "medidas preventivas" (O Dia, 10/02/2008, p.25). Em seguida a essas aparecem doenças que atingem o sistema músculo esquelético, sobretudo as LER (lesão por esforço repetitivo). Nem todas as solicitações de dispensa são atendidas. A LER é uma síndrome que raramente obtém licença, porque seus sintomas reduzem-se, geralmente, à dor, facilmente classificável como "subjetiva". As lesões em tendões e nervos só aparecem em imagens em estágios avançados, levando, em muitos casos, à aposentadoria precoce em certas categorias, como bancários, técnicos de informática etc.

5 Sabemos que um dos fins principais da revolução biotecnológica, profundamente inserida na economia mundial de mercado, é a venda de bioprodutos, de fármacos e de equipamentos biomédicos, propiciadores do prolongamento da vida, da contenção do processo de envelhecimento humano, da bioestética 
É importante assinalar esta constatação, pois, aparentemente, o regime social do trabalho, em geral, e o ambiente de trabalho, em particular, em todas as frentes da produção (industrial, comercial e de serviços, públicos ou privados), tornaram-se hostil à vida de tal modo que, sempre que tem uma oportunidade, apesar dos riscos implicados, uma boa parte dos trabalhadores evita comparecer, ou chega depois da hora, ou sai mais cedo, e contorna como pode as normas para sua efetiva presença no emprego no número de horas assinaladas em seu contrato. Estar no trabalho atualmente não significa, necessariamente, estar em ação significativa, mesmo cumprindo adequadamente suas tarefas. A lógica do trabalho como um "apelo"(beruf) à realização de uma vocação, que Max Weber viu como o fundamento ético da sociedade capitalista (WEBER, 2004), não é a lógica do emprego atual, como se este tivesse perdido o sentido de ser trabalho ${ }^{6}$, como se o local do trabalho não fosse mais o mundo do trabalho, aquele que cada um escolhe para atuar significativamente no mundo. Se, para Marx, a essência mesma do trabalho, em função da extração da mais valia do trabalhador, era ser alienante, despida de sentido - isto é, era ser outra coisa que não o sujeito - isso não excluía, no entanto, - muito pelo contrário! - a presença de uma ética solidária no mundo do trabalho, em que os valores coletivos partilhados pelos trabalhadores geravam uma sociabilidade que poderíamos denominar cultura do trabalho, capaz de amenizar a dureza das condições de vida geradas pelo regime laboral e de gerar movimentos de contestação e revoltas ou de comemorações de conquistas. Apesar da exploração e do sacrifício coletivos, era lá, no mundo do trabalho, lá mesmo no

e do controle de doenças degenerativas, inclusive por meio de manipulação genética. Esta poderia, em futuro próximo, garantir a prevenção da geração de fetos ou de nascimentos "problemáticos". Isto é, de seres humanos potencialmente portadores de doenças graves ou estigmatizadas nesta sociedade. Este não é o tema de análise deste texto, certamente um tema forte na área disciplinar da Bioética. Vamos, entretanto, deixá-lo aqui assinalado.

6 A lógica do emprego, na fase atual do capitalismo neoliberal é a do mercado, havendo mesmo "pregões" de vagas oferecidas a grupos específicos de trabalhadores, de acordo com as necessidades das empresas e dos setores da economia, variáveis em tempo e espaço, deslocando-se a força de trabalho em função dessas necessidades, e sendo descartada quando essas necessidades cessam. Daí, também, a precariedade do emprego. 
emprego, que se desejava estar, pois era na fábrica, na mina, no estaleiro, que "aconteciam as coisas".

No regime tecnológico do trabalho pós-industrial e pósfordista, em grande parte automatizado e virtual, é como se não fosse mais necessária a intervenção - às vezes mesmo a presença - humana (ao contrário, é sempre necessário prevenir o "erro humano"). O trabalhador é reduzido à condição de indivíduo. As tarefas, individualizadas e muitas vezes isoladamente cumpridas, no que concerne aos técnicos qualificados de todos os ramos (o que inclui certamente os pesquisadores), devem ser executadas em silêncio, no ritmo rápido e preciso das máquinas, virtuais ou não, em busca de uma produtividade otimizada. Esta busca de otimização de produtividade, aliás, tornou-se o objetivo que dá sentido às atividades da vida social da maior parte dos técnicos e pesquisadores. Para uma parte crescente dos mesmos tornou-se verdadeira obsessão. ${ }^{7}$

Assim, pudemos também constatar, nos dois últimos trabalhos mencionados, ao contrário da tendência ao absenteísmo entre trabalhadores em geral (de qualificação baixa, média ou elevada), a presença alarmantemente crescente, entre trabalhadores qualificados (entre os quais incluímos os pesquisadores acadêmicos), dos workaholics, isto é, daqueles trabalhadores incapazes de distanciarem-se das atividades laborais, mantendo-se em contato com elas, ainda que virtualmente, sete dias na semana, por mais de doze horas ao dia, sem separar horas previstas para lazer e descanso (freqüientemente até de refeições, que são feitas no local do trabalho, muitas vezes em reuniões), sofrendo do distúrbio, denominado no mundo do trabalho anglo-saxão de "fobia de férias": a incapacidade de sair de férias, por poucos dias que seja, e perder seu lugar, ou de encontrar um "vazio de sentidos" no lugar para onde dirigem-se. Uma porcentagem não desprezível destas pessoas chega a adoecer e morrer por excesso de trabalho, não detectado

7 Quando nos referimos aqui a "técnicos qualificados" e "pesquisadores", não nos restringimos ao universo acadêmico. Porcentagem importante da força de trabalho, em seus diversos ramos, é constituída por técnicos qualificados e pesquisadores, ainda que essas "pesquisas" sejam buscas aplicadas, referidas às atividades da produção. A pesquisa é o instrumento de trabalho fundamental da produção capitalista atual, globalizada. 
a tempo por manter-se organicamente assintomático, por tratar-se predominantemente de trabalho mental ${ }^{8}$.

Nossa hipótese interpretativa, nesse caso, tem sido de que esses trabalhadores ajustaram-se tão completamente ao regime atual de produção que não conseguem mais reconhecerem-se como sujeitos fora do ambiente (físico e/ou virtual) do trabalho. Tomaram para si a identidade de instrumentos de produção ao adotarem completamente a categoria de produtividade como norma central do viver. $\mathrm{O}$ trabalho invadiu vigorosamente seu espaço de subjetividade e sua identidade é a de "empregado", seja qual for seu ofício (executivo, secretário, pesquisador, professor, médico etc.). Entretanto, são os trabalhadores técnicos mais qualificados dos grandes grupos empresariais ou das instituições públicas, ou os trabalhadores intelectuais centrados nas atividades acadêmicas, os mais atingidos pela patologia do produtivismo (LUZ, 2007). Não há mais, num setor crescente desses trabalhadores, praticamente a separação entre o existir e o produzir. Este trabalhador tornou-se, neste caso, efetivamente "instrumento de produção", para empregar a linguagem clássica de Marx; isto é, adotou a identidade daquilo que produz em seu trabalho. Geralmente, não se consegue ter outro tema de conversa que não seja sua atividade de trabalho, o que está produzindo, o que visa alcançar com seu produto, em termos de prestígio, gratificação material e simbólica, e assim por diante. Sua sociabilidade, sua forma de agir em grupo, do mesmo modo que seu discurso, apresentam-se funcionais. Sua subjetividade parece restringir-se ao mundo das atividades laborais, e o sujeito faz lembrar, por sua monotonia discursiva, os adeptos de certas seitas evangélicas pentecostais contemporâneas. ${ }^{9}$

Em suma, é nossa hipótese que exista, atualmente, uma cultura da empresa dominante no mundo do trabalho, centrada em

8 A morte por excesso de trabalho não detectado a tempo é uma das principais causas de mortalidade em paises capitalistas de ponta, como o Japão, onde figura entre os três principais problemas de saúde pública.

9 Talvez não exista coisa mais tediosa do que sentar-se perto de um grupo de funcionários ou 'executivos' em um restaurante. Sendo ou não "um almoço de negócios”, os temas de discussão restringem-se à vida da empresa (ou instituição), às estratégias do sujeito e seus aliados (ou de seu chefe) para desenvolver um "projeto", promover um "evento" etc. Os eventos são, aliás, parte indispensável da vida das organizações. 
valores individualistas, como desempenho e competição individual em favor da empresa, diferente da cultura do trabalho do capitalismo industrial, mesmo em seu período fordista, mais centrada em valores coletivos favoráveis à força de trabalho. Não é de espantar-se que a primeira pergunta que se faça a uma pessoa não seja mais "qual é o seu nome", ou "quem são seus pais", ou "do que gosta", ou "aspira a ser ou fazer"; mas sim "em que trabalha" ("em que é formado"). Sobretudo, "qual é seu emprego atual?".

$\mathrm{O}$ indivíduo pode ser um filósofo, um gênio artístico, um potencial inventor, um técnico capaz de transformar um objeto inutilizado em outro, mais funcional e novo, figuras que existiram e que tanta importância tiveram na Renascença (como Leonardo da Vinci, por exemplo, que era tudo isso). Pois, se o sujeito não tiver uma profissão e, preferencialmente, um emprego, não passa de um "zé-ninguém", de um "looser" (perdedor, fracassado), para empregar o termo em inglês ${ }^{10}$. E há tão poucos empregos para tantos aspirantes a serem empregados! Entre os jovens franceses, por exemplo, pode passar-se uma década entre formatura e primeiro emprego ${ }^{11}$.

Assim, a reflexão por nós desenvolvida evoluiu da constatação da crescente busca de cuidados em saúde em nossa sociedade à percepção de que, para uma grande parte da população, o trabalho transformado em emprego (difícil e precário) vem acarretando uma perda grave de sentidos do próprio ato de trabalhar. O que, somado ao sofrimento gerado pela perda de significados e valores coletivos implicados anteriormente na cultura e na vida social ligadas ao trabalhar, ao ser trabalhador, assim como à perda de importância e prestígio do próprio trabalho humano ${ }^{12}$ na estrutura contemporânea

10 Não é por acaso que uma das formas principais de classificar as pessoas na sociedade atual refere-se a sua situação face ao emprego: funcionário (de uma organização ou instituição), desempregado, licenciado ou aposentado. Outra forma, inseparável da primeira, refere-se a sua faixa etária: criança, adolescente, adulto, idoso. Categorias conectáveis à situação de trabalho: ainda não faz parte ou já saiu do mercado de trabalho.

11 Parte dos movimentos de revolta dos jovens franceses está diretamente ligada à inserção tardia no emprego, mesmo precariamente, ou à incapacidade do mercado de absorvê-los, sejam de origem imigrante ou não.

12 No trabalho anterior a este (LUZ, 2007) exemplificamos esta "perda de importância” pela desconstrução, ou desprestígio, de várias profissões socialmente importantes na fase anterior do capitalismo, como as de professor, médico, 
de produção face à natureza das transformações tecnológicas em curso, estão gerando, em grande parte, o mal estar e adoecimento coletivos mencionados no início dessas notas (LUZ, 2004a, 2007).

Dizemos em grande parte - mas não na sua totalidade - porque é importante, a nosso ver, levar em conta, além da perda objetiva de condições de vida de parte importante da massa potencial de trabalhadores, a interiorização pelos próprios agentes inseridos na produção - os trabalhadores, neste caso - dos valores culturais relativos ao trabalho veiculados pelas organizações (ou instituições). Sem esta adesão, que garante ao mundo capitalista e suas classes dirigentes, além do poder econômico, a condução moral e política sobre a sociedade - que Gramsci denominou hegemonia (GRAMSCI, 1978) - e a colaboração efetiva para seu sucesso a partir do respeito inconteste às regras e valores da produção, tal adoecimento não seria possível, ou ao menos não seria tão frequiente.

Adoecimento coletivo, produção (regime social de trabalho) e valores (ética no trabalho) estão, de acordo com nossa perspectiva, intrinsecamente ligados na conjuntura capitalista mundial. E a adesão dos sujeitos aos valores dominantes está especialmente presente num segmento específico de trabalhadores qualificados de que somos parte e acompanhamos há anos (mais de três décadas): os docentes/pesquisadores ${ }^{13}$ da pós- graduação (LUZ, 2005a, 2007).

\section{Temas complexos, campos interdisciplinares: para interpretar a perda de sentidos e ética no trabalho, sofrimento e adoecimento coletivos no capitalismo contemporâneo}

Acreditamos que não é mais possível compreender, interpretar ou explicar fenômenos contemporâneos de grande complexidade,

bancário e contador, por exemplo. Sem serem "intelectuais tradicionais" no sentido gramsciano, eram, entretanto, profissionais de carreiras prestigiosas, material e culturalmente importantes pelo papel social e econômico que preenchiam, até pelo menos os anos 60s do século passado.

13 Neste caso preferimos manter o travessão, pois estes agentes institucionais vêem-se antes de tudo como pesquisadores que informam, e não como mestres que formam outros (mestres) pelo ensino. São, antes de tudo, cientistas que transmitem aos alunos informações sobre seus métodos e resultados de pesquisa. 
como os que dizem respeito à sobrevivência da vida humana em sociedade - ou mesmo como espécie no planeta - unilateralmente, do ponto de vista epistemológico. Seja como decorrência objetiva de estruturas sociais que produzem tais fenômenos - determinismo social - seja como efeitos de causalidades biológicas externas, a partir de agentes patogênicos, ou internas, como determinação genética (determinismo biológico). Ou ainda, como fruto de distúrbios ou desequilíbrios individuais de natureza psíquica (determinismo psicológico). Tampouco, a partir de pesquisas mono (ou mesmo pluri) disciplinares centradas no modelo disciplinar moderno explicativo causal. $\mathrm{O}$ mal-estar e adoecimento coletivos é um destes "fatos sociais totais" 14 que, similarmente ao suicídio na sociedade capitalista de um século atrás, analisado por Émile Durkheim (1978), solicita atualmente um olhar plural, do ponto de vista epistemológico e da pesquisa social, que designamos "abordagens interdisciplinares". 15

Com esta proposta queremos ratificar a interdependência humana no plano vital - mais do que simplesmente no plano biológico, também no psíquico e no da vida "em comum" com outros

14 As aspas são mantidas na expressão "fatos sociais totais" para sublinhar o caráter metafórico da alusão ao conceito de Mauss, e quer assinalar que tais fatos têm irreversível significação multidimensional.

15 Em sua obra O Suicídio, de 1897, às portas do século XX, Durkheim reafirma sua busca de comprovação da existência do social como dimensão efetiva do real, isto é, da sociedade como estrutura objetiva, e explicativa de condutas individuais e coletivas, o que pode ser comprovado pela atividade da pesquisa. Busca também diferenciar o 'fato social' do 'fato natural', ou 'físico', do 'fato psíquico', subjetivo, afirmando o primado do social. A sociedade torna-se a fonte legítima de explicação de fenômenos coletivos humanos. Evidentemente, tratava-se, naquele contexto, da legitimação da sociologia (e outras ciências sociais) como campo de pesquisa científica e de interpretação de realidades humanas, face à controvérsia com as "ciências físicas" e "psicológicas". Controvérsia não encerrada um século depois, vista a veemência com que Moscovici (MOSCOVICI, 1988) ataca as concepções de dois clássicos da sociologia: Durkheim e Weber, como reducionismo social. Neste artigo estamos tentando ver como essas dimensões, dicotômicas nas perspectivas teóricas e metodológicas das disciplinas do século XIX não mais podem manter-se como tal, sugerindo a colaboração interdisciplinar dos três campos. O "natural" (biológico, físico, ambiental), o "subjetivo" (psíquico, individual) e o "social", vistos como departamentos disciplinares da modernidade, não são mais capazes de, isoladamente, interpretar a complexidade de certos fatos envolvendo a vida humana. 
seres humanos, que denominamos sociedade. Em outros termos, não há fato humano que não implique ao mesmo tempo os planos biopsíquico e social. O vital humano é pluri dimensional. Outro modo de dizer isto é o fato de que a subjetividade humana, mais do que simplesmente psíquica, é também biológica e social, ou seja, é perfeitamente objetiva em suas três dimensões.

As dicotomias: subjetivo versus objetivo, psicológico versus biológico, ou individual versus coletivo e os reducionismos que ensejam são artefatos ideológicos resultantes das separações disciplinares que estão na origem das ciências humanas e seus regimes de produção discursiva. São dicotomias geradas pela episteme da modernidade clássica (FOUCAULT, 1965), que distingue (e separa, hierarquizando, em termos discursivos) o que é natural (a natureza, o biológico, o físico) do que é individual (o sujeito psíquico, irredutível ao plano biológico), com identificação do individual ao subjetivo (destituído de valor epistemológico), e o que é social (construção humana convencional) (LUZ, 2004b).

É certo que, durante os anos 80 do século passado, as ciências humanas, em crise paradigmática, buscaram superar as dicotomias internas de suas matrizes teóricas, relativas às questões da "estrutura versus sujeito" (ou "coletivo versus individual"). Nas ciências sociais como um todo, a hegemonia dos modelos totalizadores de interpretação marxistas ou funcionalistas ${ }^{16}$ foi, em parte, supera$\mathrm{da}^{17}$, e a micro sociologia, a partir das teorias da ação social influen-

16 As teorias estruturalistas, centradas na noção de estrutura social, tiveram suas vertentes mais importantes dominantes na sociologia e na política, entre as décadas de 40 e 70 do século XX, sendo representadas pelo marxismo e o funcionalismo americano. Embora a concepção, o conteúdo mesmo da noção de estrutura fosse completamente diferente nas duas teorias (no marxismo centrava-se na teoria da evolução histórica dos modos de produção social, e no funcionalismo na teoria dos sistemas e subsistemas componentes do sistema social), tinham em comum a visão de determinação da sociedade a partir de uma totalidade definida como estrutura.

17 Os "macro modelos", embora tenham perdido impacto nas ciências sociais como marco teórico dominante, são ainda muito importantes na compreensão e interpretação de "macro estruturas", tais como: a sociedade mundial contemporânea, com suas características sócio-econômicas consequientes ao capitalismo globalizado; o contexto social das grandes transformações econômicas em andamento (o papel da economia financeirizada no mundo atual, 
ciadas pela abordagem fenomenológica ganharam, a partir de então, espaço interpretativo importante na sociologia e na antropologia, analisando sujeitos e suas interações. Entretanto, esta superação não parece ter produzido ainda um grande debate interdisciplinar, com avanço metodológico ou teórico significativo nas ciências sociais em geral - na sociologia e na política, em particular - à exceção de alguns grandes nomes da segunda metade do século XX, como Pierre Bourdieu (BOURDIEU, 1988), no sentido de buscar clarificar a partir da pesquisa os modos de conexão desenvolvidos entre macro estruturas sociais e o modo de ser e viver das pessoas. Dito de modo inverso: entre os sujeitos (os agentes ou atores), sua subjetividade, suas ações e interações sociais, e sua adesão às normas (estruturas estruturantes) que modelam suas práticas, enquadrando, do nascimento à morte, a partir de organizações sociais estáveis e de instituições, seu modo de ser, pensar e agir (ibidem).

Na Sociologia e na História (e mesmo na Antropologia), ainda que com resistências, este esforço vem crescendo, apesar de dificuldades teóricas e metodológicas para desenhar novas linguagens, métodos e abordagens teóricas interdisciplinares; pois o modelo disciplinar ortodoxo ${ }^{18}$ permanece hegemônico. Em outras disciplinas das ciências humanas, entretanto, sobretudo as ligadas ao psiquismo humano - as assim chamadas disciplinas "psi" (psicologias e psicanálise) - a dificuldade de lidar com a dimensão sócio-cultural do psiquismo humano não foi, até o momento, superada, apesar dos consideráveis avanços da psicanálise, em pauta desde o fim

as "convulsões" provocadas por mega fusões, a volatilidade dos capitais, e a instabilidade gerada no sistema); as mudanças no regime social do trabalho e na seguridade social; seus efeitos sobre as populações (concentração progressiva da riqueza, exclusão social, destruição do meio ambiente, miséria, violência etc). Não há, entretanto, "teorias de médio alcance" (MERTON, 1965) que interpretem as consequiências desses macro processos no cotidiano do viver das pessoas, ou da desestruturação (e até destruição) das organizações e das instituições que configuram moral e politicamente o sistema vigente.

18 No modelo disciplinar ortodoxo, originado, como afirmamos, na modernidade clássica, cada ciência constrói seus objetos, seus métodos e suas teorias explicativas, às vezes em oposição aos de outra disciplina, ou de disciplinas de outro campo. A comprovação de verdades tem um papel importante neste modelo. 
do século passado ${ }^{19}$. Pelo contrário, o reducionismo explicativo biológico avançou na Psiquiatria e na Psicologia com grande intensidade nas duas últimas décadas, em função do desenvolvimento expressivo das pesquisas em disciplinas ligadas ao conhecimento da anatomia e das funções do cérebro. Isto tem gerado, por outro lado, dado seu caráter normativo, novas controvérsias no interior do campo das ciências "psi" e humanas. ${ }^{20}$

No interior das ciências humanas permanece, portanto, a dicotomia reducionista das matrizes teóricas originadas na segunda metade do século XIX, impedindo interpretações mais complexas, portanto mais completas e satisfatórias, de fenômenos da atualidade que considerem a interconexão da vida social com a subjetividade dos seres humanos envolvidos, e suas consequiências concretas na ordem da vida desses seres, isto é, de seu funcionamento bio-psíquico, de sua saúde ou, genericamente, de sua vitalidade.

Por outro lado, aparentemente, o que Talcott Parsons denominou de a "grande teoria" nos anos 60 (PARSONS, 1966), designando com isto uma teoria geral compreensiva dos sistemas (modelo do sistema), isto é, interpretativa das várias dimensões do viver humano (ambiente, personalidade, subsistema cultural, estrutura social), está sendo retomado atualmente por alguns autores das ciências sociais, como Edgard Morin (1990), em termos de novos paradigmas explicativos ou de modelos transdisciplinares de interpretação, ${ }^{21}$

19 A psicanálise experimenta, desde fim do século XX, atestada por literatura internacional e nacional, que não constitui objeto dessas reflexões, um renascimento teórico importante, influenciada em parte pela reflexão freudiana sobre o declínio da civilização ocidental e ao incluir em sua abordagem do sujeito, a partir da filosofia, da moral e das artes, aspectos éticos e sócio culturais presentes em manifestações do inconsciente. Busca, ao mesmo tempo, superar conceitualmente o próprio pensamento psicanalítico freudiano relativo à sua herança biomédica, ligada às patologias do psiquismo. Ver referências no fim do texto.

20 Uma das questões controversas, do ponto de vista social e da subjetividade das pessoas, é o processo avassalador, em curso, de fármaco-medicalização dos humores, dos sentimentos e emoções, e das capacidades cognitivas dos sujeitos. Este processo tem tido caráter nitidamente normatizador.

21 O modelo da complexidade, do sociólogo Edgard Morin é o exemplo mais importante no caso das ciências sociais do último terço do século XX. Propõe-se a sintetizar, num novo paradigma, as diferentes dimensões da vida humana, superando as dicotomias disciplinares da modernidade na teoria e na pesquisa. 
ou então a partir de ensaios teóricos temáticos sobre macro características culturais marcantes da pós-modernidade (BAUMAN, 2001; MAFFESOLI, 2007) ${ }^{22}$

Entretanto, cremos que esses novos modelos e análises, por inovadores e fascinantes que sejam, não afetam a lógica de funcionamento disciplinar das ciências humanas, principalmente no que concerne a linguagem e as formas de pesquisar, acabando por constituir-se em novas teorias que se somam às existentes, criando partidários e oponentes. Talvez porque uma "grande síntese" teórica interdisciplinar não é mais possível, em função do avanço metodológico e discursivo especializado em cada uma das disciplinas do campo das ciências sociais e humanas durante o século XX. Este avanço desenvolveu-se sem interrupção, adensando as disciplinas com novos temas estratégicos, novos objetos, novas teorias, novos métodos de pesquisa. O mais importante - ou mais urgente - neste momento, talvez seja propor, ao invés dos grandes modelos ou das teorias totalizadoras do passado, a construção de passos de aproximação interdisciplinar, a partir do pesquisar em conjunto, a partir de diferentes campos e áreas mono ou pluri disciplinares, temas estratégicos comuns (os "fatos totais" mencionados no início) que dizem respeito à questão da vida humana nas suas distintas dimensões. Isto é, partir do "solo" da prática da pesquisa em direção ao "alto" do modelo complexo (interdisciplinar), e não o contrário, como é a tradição ocidental. Para este objetivo, a categoria de campo de Pierre Bourdieu (BOURDIEU, 1988) representa, a nosso ver, um instrumento mais útil e mais fértil, metodológica e teoricamente, do que a categoria de ciência (ou de disciplina científica).

O fato de estarmos inseridos há mais de três décadas em um campo interdisciplinar de pesquisa, de elaboração conceitual

22 Zigmunt Bauman, assim como Michel Maffesoli, entre outros autores contemporâneos das ciências sociais, analisam macro características culturais típicas da pós-modernidade (em si mesma uma noção controversa), como a questão do imaginário, da corporeidade, do fluxo volátil da sociabilidade e dos sentimentos no contexto atual dos sujeitos individuais e grupais, e as consequiências que geram no ritmo do viver social e no próprio individualismo pós-moderno, com suas características específicas. Há grande influência da filosofia, da literatura, e da(s) teoria(s) da comunicação social nesses ensaios teóricos. Ver bibliografia ao fim do texto. 
e propostas de intervenção, denominado, a partir do fim dos anos 80, de Saúde Coletiva, propiciou-nos um distanciamento produtivo em relação à Sociologia e ao campo das ciências sociais como um todo. Tivemos que lidar com os obstáculos (epistemológicos, metodológicos, políticos) da realidade multidisciplinar de um campo "misto" de saberes e práticas, em que a lógica da produção de verdades (paradigma da ciência) não é separável da lógica da eficácia (paradigma da saúde, ou da vida).

A coexistência num só campo de múltiplos saberes científicos (ou disciplinas científicas) e de dois paradigmas de construção, nas práticas e nos discursos (o das verdades e o da eficácia), do que é para ser visto como legitimamente verdadeiro (por sua eficácia), forçou-nos a desdobrar um olhar previamente mono disciplinar (sociológico) em uma ótica multidisciplinar (da diversidade no pesquisar) e em uma dialógica de construção de objetos (LUZ, 2003). A convivência com os três subcampos do campo da saúde coletiva - ciências humanas e sociais, política e planejamento, e epidemiologia - tematizando saúde e doença e sua importância na sociedade contemporânea, ${ }^{23}$ acabou por mostrar-nos porque um aparente enigma, o do paradigma disciplinar, era de óbvia interpretação, mas não conseguíamos decifrá-lo: um só campo de saberes disciplinares não fornece interpretações complexas, suficientemente abrangentes, dos fenômenos que atingem atualmente a vida humana em suas várias dimensões, isto é, para os "fatos sociais totais" mencionados no início deste texto.

E entre os fatos sociais complexos que demandam interdisciplinaridade no pesquisar e no interpretar - poderíamos designá-los,

23 O campo da Saúde Coletiva, tradicionalmente conhecido como "Saúde Pública", inserido institucionalmente na "Grande Área da Saúde" na CAPES, tem ocupado-se crescentemente da questão da interdisciplinaridade, pois seus estudos e pesquisas não se limitam mais às "doenças coletivas" (epidemias, endemias) ou às políticas públicas concernentes aos serviços de saúde. A definição da positividade da saúde como categoria fundamental do campo, gerou, a partir dos anos 90s, uma das questões que tem levado à discussão, apesar dos conflitos discursivos e políticos internos ao campo, à necessária prática da interdisciplinaridade na pesquisa, pondo em contato e interação suas três áreas principais. Deste ponto de vista, a Saúde Coletiva é um campo de vanguarda epistemológica face ao paradigma clássico. 
também, como mencionamos acima, como "temas estratégicos" - estão: a violência, as drogas, a sexualidade, os gêneros e sua polissemia na atualidade, a corporeidade e seu papel na cultura contemporânea, e o trabalho, mal estar e adoecimento coletivos. Deste, emergiu o tema que tomamos como exemplo para análise, isto é: o regime de produtividade (acadêmica, no caso em questão), a perda de valores solidários no trabalho, gerada pelo regime social da produção, e a geração de sofrimento e adoecimento coletivos. Com um breve desenvolvimento deste tema encerraremos este texto.

\section{Políticas recentes de ciência e tecnologia, produtividade acadêmica, perda de valores solidários e geração de sofrimento e de adoecimento entre pesquisadores}

Para não corrermos o risco de repetições, e re-situando as presentes notas no contexto do curso de uma trajetória reflexiva, é necessário reafirmar que nos últimos 30 anos houve uma progressiva inversão histórica de prioridades nas políticas públicas de educação, face à ciência e ao desenvolvimento da tecnologia, do papel do ensino universitário na formação dos recursos humanos academicamente avançados no País (LUZ, 2005a, 2005b, 2007). A pesquisa passou a ser o meio e o fim dessa formação, porém esta clara priorização institucional, manifesta nas agências institucionais públicas de fomento ao desenvolvimento científico - em si mesma positiva e necessária, face ao nosso passado educacional - teve como consequiências pedagógicas, entre outros efeitos: i) a perda progressiva da importância da educação baseada no ensino do saber disciplinar canônico (conhecimento teórico e prático acumulado nas disciplinas); ii) a perda da construção da mentalidade do mestre, o agente educacional formador de novas gerações de mestres e de verdadeiros cientistas, isto é, do sujeito capaz de inovar, criando, teorizando e praticando sua ciência, em interação disciplinar com outras, ou não; iii) a perda da identidade positiva de ser um professor. O ensinar como função na pós-graduação e, sobretudo, na graduação, considerando-se até o início dos anos 80 , a atividade fim nobre da universidade foi sendo, ao longo dos anos 90, desprestigiada, 
"encolhida" juntamente com os prazos de términos dos cursos de pós-graduação (mestrado e doutorado), e reduzido quase que à transmissão de informações sobre as linhas de pesquisa em andamento nos programas de pós-graduação (LUZ, 2005).

Do nosso ponto de vista não é necessário, nem desejável, que haja separação entre ensino universitário e pesquisa. Tornou-se mesmo vital para a sobrevivência da universidade contemporânea que esta ligação seja uma contínua interconexão alimentadora (LUZ, 2005, 2007). Quanto mais a pesquisa expandir-se como práxis do aluno no ensino universitário como um todo, e não apenas na pós-graduação, mais a possibilidade de gerar conhecimentos e tecnologias úteis para a sociedade crescerá. Estamos de acordo com as políticas públicas de ciência e tecnologia em curso há pelo menos duas décadas. Para superar o atraso, a estagnação econômica ou a dependência tecnológica de países como o Brasil, é fundamental que o ensino universitário como um todo (cremos que, até mesmo, o ensino médio, técnico, ou não) nutra-se da prática da pesquisa, não importando os campos de disciplinas científicas - físicas, biológicas ou humanas.

Mas a crença na superação do atraso ou dependência tecnológica apenas pelo "acertar o passo" com a economia globalizada, a partir da ciência e tecnologia, levando necessariamente ao crescimento econômico, não garante, como ensinaram os mestres de economia política de meados do século passado (TAVARES \& FIORI, 1997; FURTADO, 2001), crescimento sustentável permanente. Muito menos desenvolvimento social, sem o qual o primeiro não tem sequer garantia de estabilidade.

Tomar o crescimento econômico ou o desenvolvimento tecnológico como sinônimo de desenvolvimento social, e priorizálo como política pública no terreno educacional é uma escolha política de Estado passível de gerar, a médio e longo prazos, uma tragédia social, através do fosso abissal que, fatalmente, separará os socialmente "incluídos" e os "não-incluídos" na ordem "altamente desenvolvida” em termos de tecnologia científica. Mas, de fato, esta parece ter sido a aposta de política pública educacional das duas últimas décadas, pelo menos na área dos recursos humanos avançados, isto é, da pós-graduação estrito senso. Em outras palavras, a aposta institucional de priorizar a pesquisa na educação 
pós-graduada tornou secundária a formação dos mestres ${ }^{24}$, por restringi-la aos doutores dos programas de pós-graduação, por meio de financiamento maciço de linhas de pesquisa, atualmente induzidas por editais das agências de fomento à ciência e tecnologia, concentradas em grupos de pesquisa considerados excelentes, ou de pesquisadores bolsistas de produtividade. Dito de outro modo: minimizou-se a importância dos reprodutores da mentalidade do pesquisar e da capacidade de inovar pela reflexão crítica, capazes de sintetizar (superando ou acrescentando), com sua pesquisa atual, a tradição canônica (o saber acumulado) das disciplinas.

Outro efeito institucional que consideramos perverso, indissociável do primeiro, foi a desvalorização da função do professor, o agente especializado no ensino de sua disciplina, Perdeu-se, com isto, a dignidade profissional da carreira de professor universitário ${ }^{25}$. Entretanto, a consequiência mais séria, do ponto de vista institucional, talvez seja a transformação da universidade, pelo processo em curso no seu nível mais elevado de formação (o da pós-graduação estrito senso) em "agência de operação" de projetos de pesquisa financiados por editais governamentais ou por fundações internas ou externas à instituição ${ }^{26}$. Cremos que o efeito institucional perverso

24 Não nos referimos aqui ao nível inicial de titulação da pós graduação estrito senso, e sim ao significado tradicional do termo mestre, aquele que ensina um "métier", inclusive o de pesquisador, que socializa com os alunos o conhecimento que acumulou, ao longo de sua vida, com a experiência de leitura, reflexão e pesquisa.

25 Estamos cientes que a desvalorização do ensino e da figura do professor não se restringe ao alto da pirâmide educacional. Pelo contrário, a perda de prestígio da profissão do professor, mencionada no início destas páginas em nota, começou pela "base da pirâmide", isto é, pelo ensino fundamental. Uma professora primária, do início do século XX e até parte da segunda metade, era uma figura social prestigiosa, assim como o médico, o advogado e o bancário. No início do século XXI é a candidata a uma profissão insegura, pelos riscos de agressão física envolvidos em certas áreas urbanas, e extremamente mal remunerada, se considerarmos sua importância social. Em metrópoles como o Rio de Janeiro uma professora do ensino de primeiro grau costuma receber um salário menor que o de uma empregada doméstica de classe média.

26 Nosso interesse central aqui não é a macro discussão política em curso no meio acadêmico sobre a "privatização" da universidade por meio de fundações de pesquisa, ou a questão moral da corrupção possibilitada pelas mesmas que tem sido motivo de noticiário na mídia, mas sim a distorção das funções nobres do ensino e da pesquisa pela gestão ou administração de "recursos para 
das fundações universitárias é o que poderíamos denominar "desvio de função”, com as sérias consequiências que acarreta para o ensino. Ao privilegiarem-se entidades de foro particular, especializadas na captação e na gerência de recursos para a pesquisa, no interior dos programas de pós-graduações, em unidades ou outros setores da própria universidade, aumenta-se o fosso já existente entre as funções do ensino e da pesquisa, tanto nos planos infra-estrutural e administrativo, quanto no acadêmico, tornando-se a pós-graduação subsidiária das atividades de pesquisa dos grupos financiados ${ }^{27}$

A função ensino, por sua vez, não é "financiada" por nenhuma entidade, a não ser os cursos de pós-graduação latu sensu, normalmente por meio das taxas administrativas, embora haja mudanças também neste setor. Em geral são cursos de especialização ou aperfeiçoamento voltados para um mercado específico de trabalho. Quanto à graduação, foi deixada em estado crítico nas duas últimas décadas. Enquanto isto, as atividades de pesquisa, concentradas nos "melhores doutores" (aqueles com produtividade de pesquisa elevada, de acordo com critérios estabelecidos pelo banco de dados Lattes, do CNPq) e nos "melhores programas" (aqueles programas de mestrado e doutorado com nota cinco ou mais, de acordo com a CAPES) obtêm crescente incentivo por meio dos editais temáticos das agências, diminuindo-se ao mesmo tempo, dramaticamente, o financiamento à demanda de fluxo, denominada, em parte pejorativamente, "demanda de balcão"; isto é, projetos provenientes de pesquisadores, individuais ou grupais, potencialmente originais e inovadores. Penalizam-se, com a política da "excelência da pro-

a pesquisa”, pelas fundações, captados em agências estatais ou privadas, e as situações de desigualdade institucional que é capaz de gerar.

27 Os professores de Programas de pós-graduação em atuação nos cursos de graduação de sua(s) disciplina(s) (maioria dos casos no país) vêem-se em situação de crônico esgotamento físico e mental, por terem de desempenhar todas as atividades concernentes à pesquisa (desde a execução e administração dos projetos, até os relatórios, e seus "produtos qualificados", como eventos, livros, patentes, e-sobretudo- artigos), além de encarregarem-se das pesadas tarefas do ensino na graduação, em geral cansativas, dado o número excessivo de alunos, ou o desconforto motivado pela reiterada carência de recursos didáticos e infra-estruturais, além de serem tarefas desconectadas das atividades de pós- graduação, às quais prioritariamente consagram-se. 
dutividade", cursos emergentes de pós-graduação estrito senso (com nota 3 na CAPES), sem considerar o papel estratégico para o desenvolvimento social e educacional, na formação de recursos humanos avançados que possam estar atuando em regiões pouco favorecidas por recursos e por incentivos públicos à pesquisa (como as regiões Norte, Nordeste e Centro-Oeste).

Do nosso ponto de vista, essa distribuição desigual de recursos, aparentemente justa (pois centrada na excelência acadêmica), mas de fato portadora de desigualdade institucional, tem como efeito perverso o desencadear de uma competição desenfreada entre indivíduos, grupos de pesquisadores e instituições pela obtenção de recursos para a pesquisa (LUZ, 2007). Apesar do inegável apoio das agências de ciência e tecnologia (ascendente em termos relativos, como acentuamos atrás), este permanece nitidamente insuficiente para atender ao crescimento explosivo da demanda qualificada de pesquisadores na última década. Considerada a ausência de investimentos privados em pesquisa no país, há um processo em curso de estatização da função pesquisa acadêmica, ao tempo em que a função ensino (crescentemente privatizado), tende a reduzir-se, na universidade pública, à lógica da reprodução de resultados da atividade de pesquisa, isto é, dos produtos que supõem (LUZ, 2005a, 2005b), na ótica da produtividade.

Outro efeito perverso destas políticas e estratégias institucionais, focando-se o campo do ensino universitário, tem sido a formação insuficiente dos egressos dos cursos, tanto de graduação como os de pós-graduação, objeto central de interesse destas notas. Pode haver mesmo formação de má qualidade, por falta de informações sistemáticas e densas sobre os núcleos duros dos saberes de seus campos disciplinares. Esses conteúdos demandariam muito mais atenção e tempo de estudo que o dispensado atualmente para uma boa formação pós-graduada. É necessário acentuar também que as políticas centradas no financiamento seletivo de projetos de pesquisa na pós-graduação têm gerado a formação de "especialistas em linhas de pesquisa”, os quais ignoram quase tudo de seu campo disciplinar, mesmo no que concerne às pesquisas na área como um todo. Mas, talvez, o mais perverso efeito pedagógico seja os programas formarem professores incapazes de ensinar conteúdos canônicos 
densos de suas disciplinas e de instruírem, em função de processos apressados e insuficientes de orientação acadêmica e pesquisadores pouco qualificados para exercerem plenamente seu ofício.

Em outras palavras, são formados, com estas políticas e estratégias institucionais, pesquisadores e docentes incapazes de ensinar a "aprender a aprender" (uma atitude típica do habitus de pesquisador), para empregar a expressão de Minayo $(2007)^{28}$. Tais recursos humanos acadêmicos aprenderam, prioritariamente, a desenhar um projeto de pesquisa (LUZ, 2005a), capaz de angariar recursos e de gerar produção no estrito prazo da realização de seus cursos (dois anos para o mestrado e quatro para o doutorado), conforme as normas das agências de fomento à pesquisa ou, mais simplesmente, as agências de ciência e tecnologia ${ }^{29}$. São profissionais treinados para competir por recursos e para obterem reconhecimento por sua produtividade sem que uma ética profissional concernindo o caráter público da produção científica, o reconhecimento aos seus professores e o respeito aos seus pares tenham-lhes sido transmitida com a mesma urgência e intensidade (LUZ, 2007). Tendem a competir como indivíduos num mercado de empregos. Desconhecem, como grande parte de seus instrutores, que são força de trabalho qualificada, isto é, antes de tudo uma coletividade, exercendo uma função pública, tendo portanto que prestar contas à sociedade como comunidade.

Enquanto não se perceberem como tal e adotarem os valores éticos de solidariedade compatíveis com sua profissão, tenderão a ser levados de um lado para o outro, ao acaso dos ventos mutáveis das políticas governamentais referentes à educação e ciência e tecnologia no desenvolvimento nacional. Ou, o que é mais provável, serão moídos na máquina dos interesses do lucro imediato, carac-

28 Cecília Minayo, cientista social do campo da Saúde Coletiva, emprega esta expressão em seu projeto de pesquisa, de avaliação dos últimos 10 anos da área de Saúde Coletiva, recentemente aprovado pelo CNPq, sob o título: "Avaliação da Pós-Graduação na Área de Saúde Coletiva sob a perspectiva dos atores, da cultura, das tendências e das várias formas de expressão acadêmica" (Cf. Projeto, 2007, pg. 12)

29 O espantoso, do nosso ponto de vista, é que não haja uma Agência reguladora efetivamente educacional. A CAPES, embora pertença ao Ministério da Educação, é uma Agência de Ciência e Tecnologia. 
terístico das firmas privadas de educação superior existentes no País. Tenderão, como seus professores, a adoecer em consequiência do excesso de atividades e face ao contínuo estresse gerado pelo regime social de trabalho vigente (com seus valores competitivos característicos) ao qual têm que submeter-se para sobreviver. Esta reflexão nos remete ao início dessas notas.

Recebido em 5 de março de 2008 Aprovado em 23 de maio de 2008

\section{Referências}

ALVAREZ, D. Cimento não é concreto, tamborim não é pandeiro, pensamento não é dinheiro! Para onde vai a produção acadêmica? Rio de Janeiro: Myrrha, 2004.

BALANDIER, G. O contorno: Poder e modernidade (Segunda parte). Rio de Janeiro: Bertrand Brasil, 1997.

BARBOSA, E. Conhecendo o conhecimento: questões lógicas e teóricas na crítica da ciência e da razão. Cadernos de Sociologia, Porto Alegre, v. 10, p. 9-35, 1998.

BAUMANN, F. Burn out : quand le travail rend malade. 2 ed. Paris: Josette Lyon, 2007.

BAUMANN, Z. Globalização: as consequiências humanas. Rio de Janeiro: Jorge Zahar, 1999.

. Comunidade: a busca por segurança no mundo atual. Rio de Janeiro: Jorge Zahar, 2001.

. Amor líquido: acerca de la fragilidad de los vínculos humanos. Buenos Aires: Fondo de Cultura Económica de Argentina, 2005.

. Vida líquida. Rio de Janeiro: Jorge Zahar, 2007.

. Medo líquido. Rio de Janeiro: Jorge Zahar, 2008.

BEZERRA JÚNIOR, B. O filme como meio de experimentação subjetiva. In: FACCHINETTI, C. (org.) Lições de psicanálise: sedução e fetiche na comunicação. Rio de Janeiro: UniverCidade, 2002. 
BIRMAN, J. Mal-estar na atualidade: a psicanálise e as novas formas de subjetivação. Rio de Janeiro: C. Brasileira, 1999.

. Pincelando coisas em imagens: uma leitura das artes plásticas. In: FACCHINETTI, C. (org.) Lições de psicanálise: sedução e fetiche na comunicação. Rio de Janeiro: UniverCidade, 2002. BOURDIEU, P. O poder simbólico. Rio de Janeiro: Bertrand Brasil, 1989.

CASTEL, R. A gestão dos riscos: da antipsiquiatria à pós-psicanálise. Rio e Janeiro: Francisco Alves, 1987.

. As metamorfoses da questão social: uma crônica do salário. Petrópolis: Vozes, 1998.

. L'insecurité sociale: qu'est ce qu'être protégé ? Paris: La République des Idées, 2003.

COSTA, J. Violência e psicanálise. Rio de Janeiro: Edições Graal, 1984.

. O risco de cada um: e outros ensaios de psicanálise e cultura. Rio de Janeiro: Garamond, 2007.

DEJOURS, C. Souffrance en France: la banalisation de l'injustice sociale. Paris: Seuil, 1998.

DURKHEIM, E. O suicídio. São Paulo: A. Cultural, 1978.

. As formas elementares da vida religiosa. São Paulo:

A. Cultural, 1978.

ELIAS, N. A sociedade dos indivíduos. Rio de Janeiro: J. Zahar, 1994.

FACCHINETTI, C. (org.) Lições de psicanálise: sedução e fetiche na comunicação. Rio de Janeiro: UniverCidade, 2002.

FURTADO, C. O mito do desenvolvimento econômico. Rio de Janeiro: Paz e Terra, 1974.

. Os ares do mundo. Rio de Janeiro: Paz e Terra, 1991.

GEERTZ, C. Nova luz sobre a antropologia. Rio de Janeiro: J. Zahar, 2001.

HANLY, C. O problema da verdade na psicanálise aplicada. Rio de Janeiro: Imago, 1995. 
HERRERA, S. Análise do sistema educativo na perspectiva teórica de Niklas Luhmann. Cadernos de Sociologia, Porto Alegre, v. 10, p. 87-105, 1998.

JOUBERT, M.; BERTOLOTTO, F. \& BOUHNIK, P. (dir.). Quartier démocratie et santé: mode de vie et santé des familles et des jeunes sur un quartier de banlieue - une recherche-action en santé communautaire. Paris: L'Harmattan, 1993.

JOUBERT, M. \& LOUZOIN, C. (dir.). Répondre à la souffrance sociale: la psychiatrie et l'action sociale en cause. Paris: Éres, 2005.

KUMAR, K. Da sociedade pós-industrial à pós-moderna: novas teorias sobre o mundo contemporâneo. Rio de Janeiro: J. Zahar, 1997.

LUZ, M. Cultura contemporânea e medicinas alternativas: novos paradigmas em saúde no fim do século XX. PHYSIS: Revista de Saúde Coletiva, v. VII (1) p.145-176, p.13-43, 1997.

. Novos saberes e práticas em saúde coletiva: estudos sobre racionalidades médicas e atividades corporais. São Paulo, Hucitec, 2003.

. Fragilidade social e busca de cuidado na sociedade civil hoje. In: PINHEIRO, R. \& MATTOS, R. (orgs). Cuidado: as fronteiras da integralidade. São Paulo: Hucitec, 2004a.

. Natural, racional, social: razão médica e racionalidade científica moderna. São Paulo: Hucitec, 2004b.

. Prometeu acorrentado: análise sociológica da categoria produtividade e as condições atuais da vida acadêmica. PHYSIS: Revista de Saúde Coletiva, v. 15, n. 1 p. 39-57, 2005a.

. O Futuro do livro na avaliação dos programas de pós-graduação: uma cultura do livro seria necessária? Interface - comunicação, saúde, educação, v.9, n.18, p.613-636, set/dez, 2005b.

- Perda de ética no trabalho acadêmico: geração de sofrimento e doença entre os trabalhadores universitários a partir do produtivismo como valor fim entre os pesquisadores. In: PINHEIRO, Roseni.; MATTOS, Ruben. (orgs). Razões públicas para a integralidade em saúde: $O$ cuidado como valor. Rio de Janeiro: CEPESC-IMS-UERJ-ABRASCO, p. 357-368, 2007. 
MAFFESOLI, M. Sobre o nomadismo: vagabundagens pós-modernas. Rio de Janeiro: Record, 2001.

. O ritmo da vida: variações sobre o imaginário pósmoderno. Rio de Janeiro: Record, 2007.

MÉDA, D. Le travail: une valeur em voie de disparation. Paris: Flammarion, 1995.

MERTON, R. Éléments de théorie et de méthode sociologique. Paris: Plon, 1965.

MERTON, R.; BROOM, L. \& COTTRELLJÚNIOR, L. (eds.). Sociology today: Problems and Prospects. New York: Harper Torchbooks, 1965.

MORIN, E. Introdução ao pensamento complexo. Lisboa: Piaget, 1990.

MOSCOVICI, S. A máquina de fazer deuses. Rio de Janeiro: Imago, 1988.

PARSONS, T. Societes: evolutionary and comparative Perspectives. New Jersey: Prentice-Hall, 1966.

SALMON, A. La tentation éthique du capitalisme. Paris: La Découverte, 2007.

SAUL, R. Sociologias e as sínteses minimalistas. Cadernos de Sociologia, Porto Alegre, v. 10, p. 37-60, 1998.

SFEZ, L. A Saúde Perfeita: crítica de uma nova utopia. São Paulo: Loyola, 1996.

SILVA FILHO, J \& JARDIM, S. (orgs). A danação do trabalho: organização e sofrimento psíquico. Rio de Janeiro: Te Corá, 1997.

TAVARES, M. \& SERRA, J. Além da estagnação: uma discussão sobre o estilo de desenvolvimento recente no Brasil. In: SERRA, J. (org.) América Latina: ensaios de interpretação econômica. Rio de Janeiro: Paz e Terra, 1976.

TAVARES, M. \& FIORI, J. (orgs). Poder e Dinheiro: uma economia política da globalização. Petrópolis: Vozes, 1997.

WEBER, M. Ética Protestante e o Espírito do Capitalismo. São Paulo: C. das Letras, 2004. 